\title{
Development of $\mathrm{LiFePO}_{4} / \mathrm{FePO}_{4}$ Electrode for Electro-Osmotic Pump using $\mathrm{Li}^{+}$Migration
}

\author{
Jaewook Baek ${ }^{1}$, Kyeonghyeon Kim ${ }^{1}$, and Woonsup Shin ${ }^{1,2 *}$ \\ ${ }^{1}$ Department of Chemistry, Sogang University, 35 Baekbeom-ro, Mapo-gu, Seoul, 04107, Korea \\ ${ }^{2}$ Department of Biomedical Engineering, Sogang University, 35 Baekbeom-ro, Mapo-gu, Seoul, 04107, Korea
}

\begin{abstract}
Olivine structure of $\mathrm{LiFePO}_{4}$ (LFP) is one of the most commonly used materials in aqueous rechargeable lithium batteries (ARLBs), and can store and release charge through the insertion/de-insertion of $\mathrm{Li}^{+}$between LFP and FP. We have fabricated LFP and LFP/FP electrodes on titanium paper and studied their electrochemical properties in $2 \mathrm{M} \mathrm{Li}_{2} \mathrm{SO}_{4}$. The LFP/ FP electrode was determined to be a suitable electrode for electo-ostmotic pump (EOP) in terms of efficiency in water and $0.5 \mathrm{mM} \mathrm{Li}_{2} \mathrm{SO}_{4}$ solution. Experiments to determine the effect of cations and anions on the performance of EOP using LFP/ FP electrode have shown that $\mathrm{Li}^{+}$is the best cation and that the anion does not significantly affect the performance of the EOP. As the concentration of $\mathrm{Li}_{2} \mathrm{SO}_{4}$ solution was increased, the current increased. The flow rate peaked at $4.8 \mu \mathrm{L} / 30 \mathrm{~s}$ in $1.0 \mathrm{mM} \mathrm{Li}_{2} \mathrm{SO}_{4}$ solution and then decreased. When the EOP was tested continuously in $1.0 \mathrm{mM} \mathrm{Li}_{2} \mathrm{SO}_{4}$ solution, the EOP transported approximately $35 \mathrm{~mL}$ of fluid while maintaining a stable flow rate and current for $144 \mathrm{~h}$.
\end{abstract}

Keywords : Electro-osmotic pump (EOP), Aqueous rechargeable lithium-ion battery (ARLB), Lithium iron phosphate (LFP), Electrode, Lithium ion $\left(\mathrm{Li}^{+}\right)$

Received : 18 November 2017, Accepted : 23 November 2017

\section{Introduction}

Electro-osmotic pumps (EOPs) have a very simple structure composed of electrodes and membranes. When a voltage is applied across the ceramic membrane of the EOP, cations are produced by the anodic reaction and travel through the porous membrane. As the cations migrate through the membrane surface, they drag along water molecules, which transfers the momentum to the bulk of the water, generating flow and pressure [1,2]. Because of this principle of EOPs, many research groups are trying to develop new electrodes and membranes to improve the performance of EOPs. In the case of an EOP using a conventional Pt electrode, a high voltage is required to drive the EOP, which raises the problem of electrolyzing the water, generating $\mathrm{O}_{2}$ and $\mathrm{H}_{2}$. The size of the EOP itself is

*E-mail address: shinws@sogang.ac.kr

DOI: https://doi.org/10.5229/JECST.2018.9.2.85 not large, but an additional device to remove the generated gas makes it much larger. For preventing the generation of gas, we focused on the electrode reaction. We have previously reported on $\mathrm{Ag} / \mathrm{Ag}_{2} \mathrm{O}$ and PANI-PSS electrodes $[3,4]$. These electrodes are superior to conventional electrodes; however, they cannot be used for long due to dissolution. While searching for an electrode material that could enable the operation of stable EOP for a long time, we became interested in the electrode materials of lithium ion batteries (LIBs) by lithium ion transfer. $\mathrm{Li}^{+}$is an effective cation that can transport water through the membrane between the electrodes of an EOP.

LIBs have been widely used as power sources in many types of electronic devices such as mobile phones, laptops, and electronic vehicles in recent years. The first commercial LIB was developed by

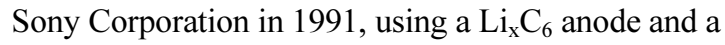
$\mathrm{Li}_{2} \mathrm{CoO}_{2}$ (LCO) cathode $[5,6]$. LCO is a cathode material for LIBs, which is widely used at present as 
a layered structure, but it is known to have the disadvantages of a relatively high price and limited specific capacitance. For the replacement for LCO the olivine structure of $\mathrm{LiFePO}_{4}$ (LFP) was known to be an inexpensive and effective alternative. LFP has $\mathrm{Li}$ atoms in half of the octahedral sites, and it is known that approximately 0.6 lithium atoms per formula unit can be extracted at a closed-circuit voltage of $3.5 \mathrm{~V}$ and the same amount can be reversibly inserted back into the structure on discharge [7]. In addition, LFP has many advantages over layered LCO, such as excellent capacitance retention, high thermal stability, nontoxicity, low cost, and aqueous system compatibility.

The insertion/de-insertion reaction of $\mathrm{Li}^{+}$in $\mathrm{FP}$ and LFP is known as follows:

$$
\mathrm{LiFePO}_{4}-x \mathrm{Li}^{+}-x \mathrm{e}^{-} \leftrightarrow \mathrm{Li}_{1-x} \mathrm{FePO}_{4}
$$

FP has $6.81 \%$ smaller volume and $2.59 \%$ higher density than those of LFP. The theoretical capacity of LFP is reported to be $169 \mathrm{mAh} / \mathrm{g}$; however, a reversible capacity of only $110 \mathrm{mAh} / \mathrm{g}$ at about $3.5 \mathrm{~V}$ vs. $\mathrm{Li}$ metal is attainable because of the poor diffusion of lithium ions between LFP and FP. In order to overcome the problem of poor diffusion, LFP should be fabricated at sizes on the order of hundreds of $\mathrm{nm}$ and coated with carbon $[8,9]$.

One of the great advantages of LFP is that it can use water as the electrolyte [10-13]. From the point of view of LIB, the use of water can replace expensive organic electrolytes, thereby lowering the cost of LIBs, reducing the danger of ignition, and enabling their use in safer environments. In addition, water is environmentally friendly and is abundant in nature [14]. Since we use diluted aqueous media as pumping solutions for EOPs, it is expected that aqueous rechargeable lithium battery (ARLB) electrode materials containing LFP can be applied as good electrode materials for our EOP concept.

After investigating the $\mathrm{Li}^{+}$insertion/de-insertion reaction of LFP/FP, we report several details concerning this new EOP electrode using LFP/FP materials on titanium paper. Detailed EOP test results are also discussed.

\section{Experimental}

\subsection{Chemicals}

The chemicals used in this study were: $\mathrm{LiFePO}_{4}$
(LFP, Sigma-Aldrich), $\mathrm{FePO}_{4} \cdot 2 \mathrm{H}_{2} \mathrm{O}$ (FP, SigmaAldrich), Super-P carbon black (Alfa Aesar), polyvinylidene fluoride (PVDF, Alfa Aesar), $\mathrm{Li}_{2} \mathrm{SO}_{4}$ (Sigma-Aldrich), $\mathrm{N}$-methylpyrrolidinone (NMP, Sigma-Aldrich). All chemicals were of analytical reagent grade and were directly used without further purification.

\subsection{Electrode fabrication and electrochemical study}

LFP electrodes were prepared by mixing $70 \mathrm{wt} \%$ of LFP, $20 \mathrm{wt} \%$ of Super-P, and $10 \mathrm{wt} \%$ of PVDF with NMP. LFP/FP electrodes were fabricated by mixing $35 \mathrm{wt} \%$ of LFP, $35 \mathrm{wt} \%$ of FP, $20 \mathrm{wt} \%$ of Super-P, and $10 \mathrm{wt} \%$ of PVDF with NMP. The mixed slurry was spread uniformly on porous titanium paper. After heating overnight at $110^{\circ} \mathrm{C}$ under $\mathrm{Ar}$, the electrodes were sonicated and washed with water. Cyclic voltammetry was performed using $\mathrm{CHI}$ 440A, CHI 600C (CH Instruments). A one-pot cell was used for CV. A platinum coil electrode was used as an auxiliary electrode and the reference electrode was $\mathrm{Ag} / \mathrm{AgCl}(3 \mathrm{M} \mathrm{KCl})$.

\subsection{EOP assembly and test}

A single silica membrane was connected symmetrically with each of the electrodes, Ag contact strips, and PC frames, and finally sealed with epoxy. The EOP was fully soaked in the pumping solution to be used before performance was measured. The EOP was controlled and monitored by an EOPump controller (KS RnD). The EOP was tested by applying $2.5 \mathrm{~V}$ for $30 \mathrm{~s}$ and $-2.5 \mathrm{~V}$ for $30 \mathrm{~s}$ as one cycle.

\section{Results and Discussion}

\subsection{Electrochemical study of LFP and LFP/FP electrodes}

Electrode fabrication methods are described in detail in the experimental section. LFP and LFP/FP can be stably fixed on Ti paper by dropcoating and drying. The electrochemical properties of the fabricated electrodes were studied by scanning at $5 \mathrm{mV} / \mathrm{s}$ in $2 \mathrm{M} \mathrm{Li}_{2} \mathrm{SO}_{4}$ solution, as shown in Fig. 1. The black line is the $\mathrm{CV}$ of the electrode made only with LFP, and the red line shows the CV of the LFP/FP electrode. The LFP/FP electrode CV shows a simple shape, implying that it is oxidized at $0.3 \mathrm{~V}$ and reduced at $0 \mathrm{~V}$. The peak current continuously increases until the $10^{\text {th }}$ cycle, which seems to require 
more time for stabilization of the LFP/FP surface. For the LFP electrode, the first reduction peak is observed at $0.1 \mathrm{~V}$ after oxidation at about $0.3 \mathrm{~V}$ in the first cycle. After the second cycle, additional peaks were observed at -0.4 and $-0.2 \mathrm{~V}$ during the oxidation process and one more peak at $-0.8 \mathrm{~V}$ during the reduction process, showing more complex behavior than the LFP/FP electrode.

In the LFP/FP electrode, the LFP and FP occur in a ratio of $1: 1$; therefore, there is sufficient $F P$ to be reduced with the acceptance of $\mathrm{Li}^{+}$during the negative scan after the LFP is oxidized. Hence, it is expected that the insertion/de-insertion of $\mathrm{Li}^{+}$only occurs in the LFP/FP electrode. In contrast, the LFP electrode is expected to have another reduction reaction of LFP in addition to the reduction of FP to LFP, since the amount of the oxidized LFP electrode converted to FP on the electrode surface is not sufficient. In addition, even if the cycle of the LFP/FP electrode continues, the shift of the peak potential is very small compared with that of the LFP electrode. The shift of

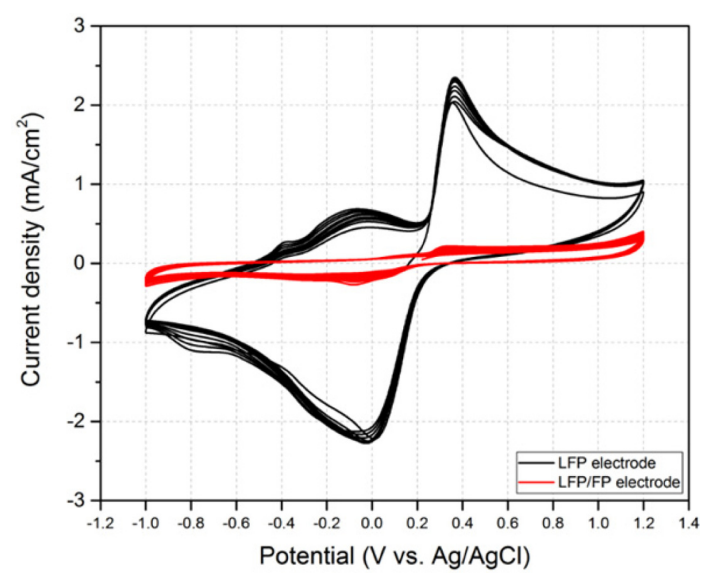

Fig. 1. Cyclic voltammogram of LFP and LFP/FP electrodes in $2 \mathrm{M} \mathrm{Li}_{2} \mathrm{SO}_{4}$ solution at a scan rate of $5 \mathrm{mV} / \mathrm{s}$. the peak potential at the LFP electrode makes it possible to predict that the electron transfer of the electrode reaction is becoming more difficult. The capacitances of the two electrodes at the second cycle were calculated to be $548 \mathrm{mC} / \mathrm{cm}^{2}$ and $81 \mathrm{mC} / \mathrm{cm}^{2}$, respectively. The capacitance of the LFP/FP electrode was more than six times larger than that of the LFP electrode. This means that the peak current increase does not occur in proportion to the amount of LFP.

\subsection{EOP test comparison of LFP and LFP/FP electrodes using water and $0.5 \mathrm{mM} \mathrm{Li}_{2} \mathrm{SO}_{4}$}

The EOP was assembled with LFP and LFP/FP electrodes. The prepared EOP was filled with water or $0.5 \mathrm{mM} \mathrm{Li}_{2} \mathrm{SO}_{4}$ and allowed to stand for $2 \mathrm{~h}$. Then, the bubbles in the EOP were removed before the EOP was tested. All pump experiments were conducted by applying $2.5 \mathrm{~V}$ for $30 \mathrm{~s}$ and $-2.5 \mathrm{~V}$ for $30 \mathrm{~s}$ as one cycle. Both materials showed potential as EOP electrodes. The transport of water through the electrode reaction can be explained as shown in Fig. 2. Table 1 shows the current and flow rate of the EOPs using LFP and LFP/FP electrodes. When water is used as a pumping solution, LFP shows a current value about three times larger than that of LFP/FP.

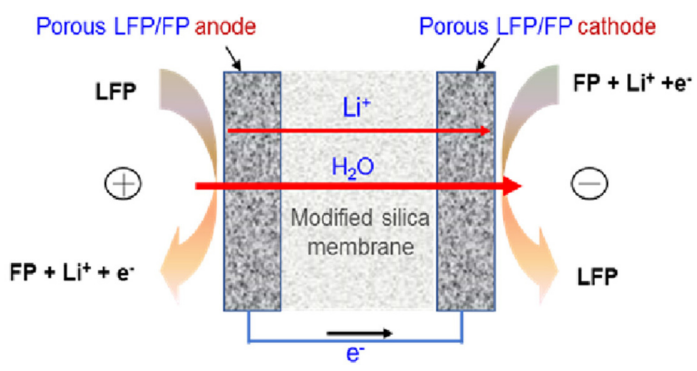

Fig. 2. Electrode reactions and flow in an EOP using LFP/ FP electrodes.

Table 1. Current and flow rate variations of EOPs using LFP and LFP/FP electrodes in water and $0.5 \mathrm{mM} \mathrm{Li}_{2} \mathrm{SO}_{4}$ as pumping solutions.

\begin{tabular}{cccccc}
\hline \hline Pumping solution & Electrode & $\begin{array}{c}\text { Initial current } \\
(\mu \mathrm{A})\end{array}$ & $\begin{array}{c}\text { Final current } \\
(\mu \mathrm{A})\end{array}$ & $\begin{array}{c}\text { Mid-point current } \\
(\mu \mathrm{A})\end{array}$ & $\begin{array}{c}\text { Flow rate } \\
(\mu \mathrm{L} / 30 \mathrm{~s})\end{array}$ \\
\hline \multirow{2}{*}{ Water } & LFP & 420 & 184 & 302 & 4.2 \\
& LFP/FP & 143 & 74 & 109 & 3.3 \\
\multirow{2}{*}{$0.5 \mathrm{mM} \mathrm{Li}_{2} \mathrm{SO}_{4}$} & LFP & 640 & 277 & 459 & 4.6 \\
& LFP/FP & 214 & 112 & 163 & 4.0 \\
\hline
\end{tabular}


However, the increase in the flow rate is only $27 \%$, which means that the efficiency of the LFP is lower than that of the LFP/FP.

In the experiments using $0.5 \mathrm{mM} \mathrm{Li}_{2} \mathrm{SO}_{4}$ as a pumping solution, LFP also showed about three times as much current as LFP/FP, but the flow rate was only increased by $15 \%$. It can be seen that the
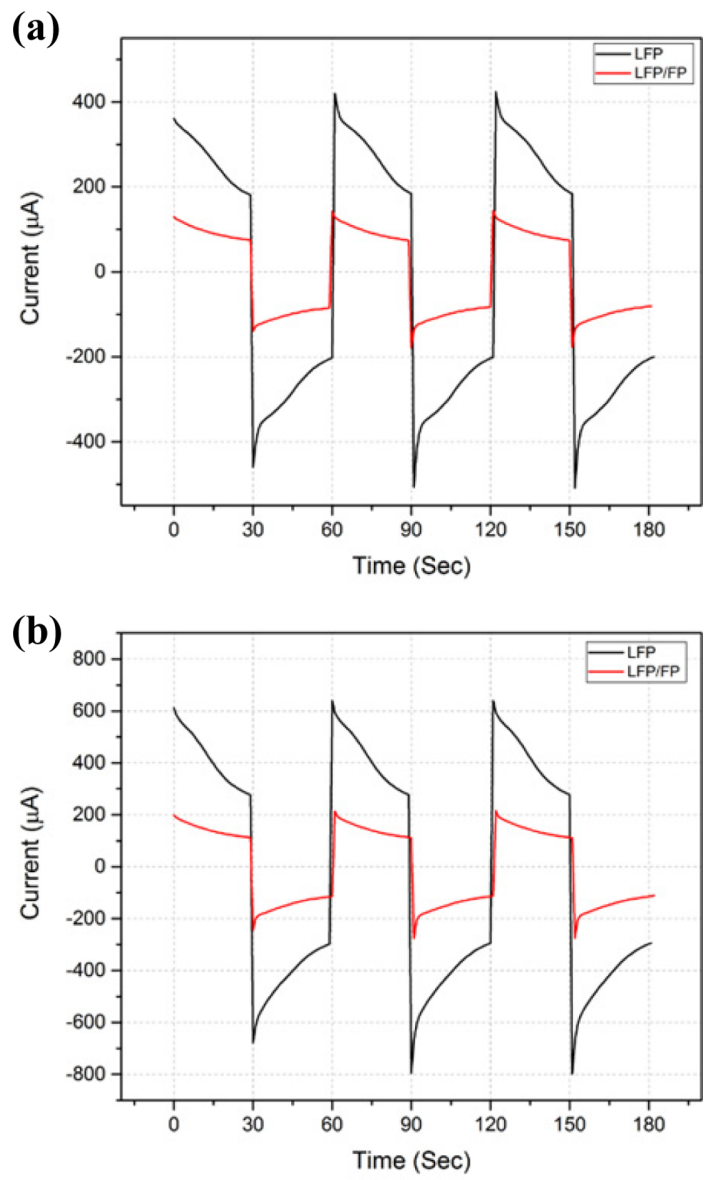

Fig. 3. (a) Current response of EOPs using LFP and LFP/ FP electrodes in water. (b) Current response of EOPs using $\mathrm{LFP}$ and LFP/FP electrodes in $0.5 \mathrm{mM} \mathrm{Li}_{2} \mathrm{SO}_{4}$. efficiency of flow rate versus current in both water and $0.5 \mathrm{mM} \mathrm{Li}_{2} \mathrm{SO}_{4}$ is good for both LFP/FP and LFP. The LFP/FP electrode showed a current increase of about $50 \%$ and a flow rate increase of $21 \%$ in $0.5 \mathrm{mM} \mathrm{Li}_{2} \mathrm{SO}_{4}$ compared with water. The efficiency of the EOP with a LFP/FP electrode in $0.5 \mathrm{mM} \mathrm{Li}_{2} \mathrm{SO}_{4}$ is still poor compared to water, but it can be seen that adding $\mathrm{Li}^{+}$to the pumping solution increases the ionic strength and flow rate of the pump. In the solution containing $\mathrm{Li}^{+}$, the LFP/FP electrode showed a $21 \%$ increase in flow rate, but the LFP electrode showed only a $10 \%$ increase. The change in current at each electrode can be seen in detail in Fig. 3. This phenomenon can be explained by the fact that since the LFP electrode does not have enough $\mathrm{FP}$ to receive $\mathrm{Li}^{+}$, the increase of $\mathrm{Li}^{+}$in the pumping solution does not lead to the movement of $\mathrm{Li}^{+}$, and cannot increase the flow rate with the increase in current. Water and $0.5 \mathrm{mM} \mathrm{Li}_{2} \mathrm{SO}_{4}$ pumping solution experiments have shown that LFP/FP electrodes are suitable for EOP, and therefore, we investigated the conditions under which LFP/FP works most efficiently.

\subsection{Cation and anion effect of pumping solution in EOP using LFP/FP electrodes}

The change in EOP performance with a change of cation was examined. The anion used was fixed as $\mathrm{SO}_{4}{ }^{2-}$ and the concentrations were also fixed to $1 \mathrm{mM}$. Three cations were used: $\mathrm{Li}^{+}, \mathrm{Na}^{+}$, and $\mathrm{K}^{+}$. Table 2 shows the change in the current and the flow rate with each cation; the change in the current can be seen in Fig. 4. When the cation was $\mathrm{Li}^{+}$, the EOP showed the best efficiency with the largest flow rate for the smallest current value. When $\mathrm{Na}^{+}$was used as a cation, the current increased by $13 \%$ as compared with $\mathrm{Li}^{+}$, but the flow rate decreased by $6 \%$, indicating decreased EOP efficiency. When $\mathrm{K}^{+}$was used as a cation, the current increased by $57 \%$ compared to $\mathrm{Li}^{+}$, but the flow rate decreased by $8 \%$, and the EOP

Table 2. Current and flow rate variations of EOPs using LFP/FP electrodes in different cation-containing pumping solutions.

\begin{tabular}{ccccc}
\hline \hline Pumping solution & $\begin{array}{c}\text { Initial current } \\
(\mu \mathrm{A})\end{array}$ & $\begin{array}{c}\text { Final current } \\
(\mu \mathrm{A})\end{array}$ & $\begin{array}{c}\text { Mid-point current } \\
(\mu \mathrm{A})\end{array}$ & $\begin{array}{c}\text { Flow rate } \\
(\mu \mathrm{L} / 30 \mathrm{~s})\end{array}$ \\
\hline $1.0 \mathrm{mM} \mathrm{Li}_{2} \mathrm{SO}_{4}$ & 326 & 136 & 231 & 4.8 \\
$1.0 \mathrm{mM} \mathrm{Na}_{2} \mathrm{SO}_{4}$ & 389 & 130 & 260 & 4.5 \\
$1.0 \mathrm{mM} \mathrm{K}_{2} \mathrm{SO}_{4}$ & 560 & 166 & 363 & 4.4 \\
\hline
\end{tabular}


efficiency was worse than when $\mathrm{Na}^{+}$was used. The radii of each ion are known as $\mathrm{Li}^{+} 76 \mathrm{pm}, \mathrm{Na}^{+} 102$ $\mathrm{pm}$, and $\mathrm{K}^{+} 138 \mathrm{pm}$. Therefore, the EOP with the LFP/FP electrode using a pumping solution with the anion fixed as $\mathrm{SO}_{4}{ }^{2-}$ performs best when the cation has the smallest radius. It might be predicted that, if the size of the cation is small, the movement along the surface of the membrane will be easier. However, it should be considered that $\mathrm{Li}^{+}$may have shown the best efficiency due to the chemical nature of the LFP, which contains $\mathrm{Li}^{+}$. In the case of EOP using an LFP/ FP electrode, it is not possible to explain the change in the performance based on the cation, but $\mathrm{Li}_{2} \mathrm{SO}_{4}$ is a better pumping solution than $\mathrm{Na}_{2} \mathrm{SO}_{4}$ and $\mathrm{K}_{2} \mathrm{SO}_{4}$ solutions.

In a similar manner, a change in EOP performance was observed when the cation was fixed as $\mathrm{Li}^{+}$and the anions were changed. The concentration of $\mathrm{Li}^{+}$ was fixed at $1 \mathrm{mM}$. In this case, the concentration of the other anions was $1 \mathrm{mM}$; thus, in the case of $\mathrm{SO}_{4}{ }^{2-}$,

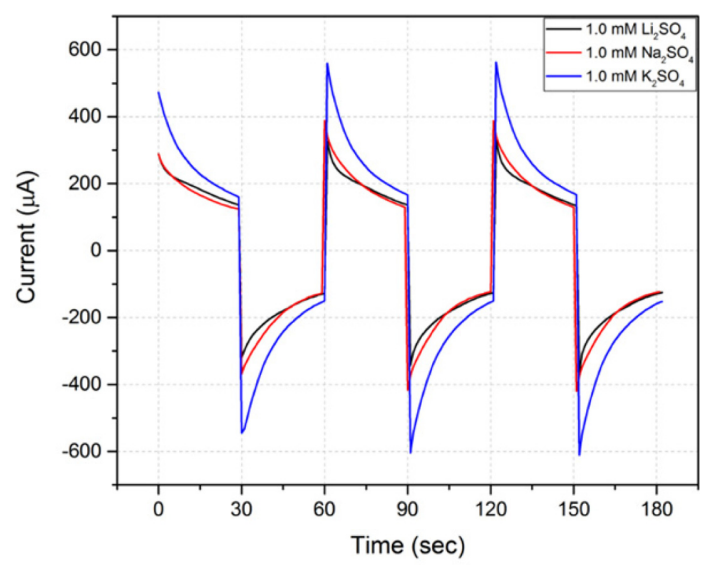

Fig. 4. Current response of EOPs using LFP/FP electrodes in different cation solutions. The anion was fixed as $\mathrm{SO}_{4}{ }^{2-}$ and the concentration was constant at $1 \mathrm{mM}$. a concentration of $0.5 \mathrm{mM} \mathrm{Li}_{2} \mathrm{SO}_{4}$ was used. As shown in Table 3 and Fig. 5, flow rate was observed to change based on the anion, but the change in the current based on the anion is not as great as the current change observed based on the cation. Looking at the radii of the anions, $\mathrm{Cl}^{-}$is $172 \mathrm{pm}, \mathrm{NO}_{3}{ }^{-}$is $179 \mathrm{pm}$, $\mathrm{ClO}_{4}{ }^{-}$is $240 \mathrm{pm}$, and $\mathrm{SO}_{4}{ }^{2-}$ is $258 \mathrm{pm} \mathrm{[15],} \mathrm{and} \mathrm{it} \mathrm{is}$ difficult to explain the relationship between the current change and the flow rate change due to anion size. The LFP/FP electrode uses the migration of cations including $\mathrm{Li}^{+}$; therefore, the influence of the negative ions might be negligible.

\subsection{Concentration effect of $\mathrm{Li}_{2} \mathrm{SO}_{4}$ and continuous running test on EOPs using LFP/FP}

Experiments using different cations and anions in the pumping solution have shown that EOPs using LFP/FP electrodes have the best efficiency using $\mathrm{Li}^{+}$, and are not significantly affected by the anion. Therefore, we fixed the pumping solution as $\mathrm{Li}_{2} \mathrm{SO}_{4}$ and

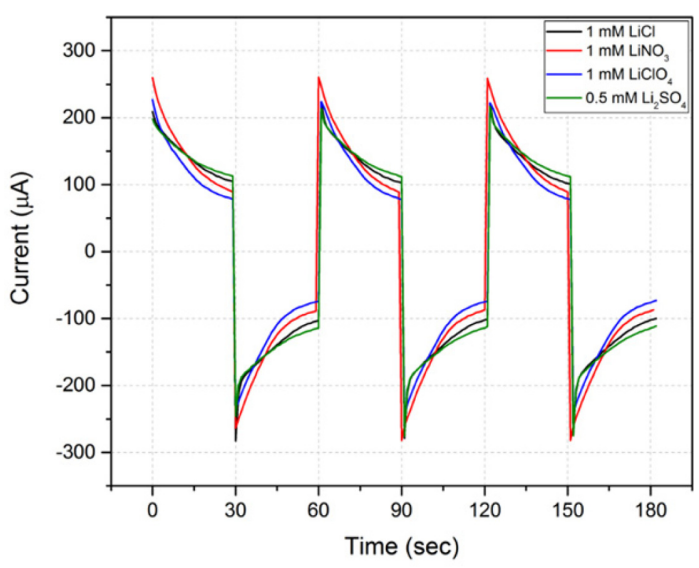

Fig. 5. Current response of EOPs using LFP/FP electrodes in different anion solutions. The cation was fixed as $\mathrm{Li}^{+}$ and concentration was constant at $1 \mathrm{mM}$.

Table 3. Current and flow rate variations of EOPs using LFP/FP electrodes in different anion containing pumping solutions.

\begin{tabular}{ccccc}
\hline \hline Pumping solution & $\begin{array}{c}\text { Initial current } \\
(\mu \mathrm{A})\end{array}$ & $\begin{array}{c}\text { Final current } \\
(\mu \mathrm{A})\end{array}$ & $\begin{array}{c}\text { Mid-point current } \\
(\mu \mathrm{A})\end{array}$ & $\begin{array}{c}\text { Flow rate } \\
(\mu \mathrm{L} / 30 \mathrm{~s})\end{array}$ \\
\hline $1.0 \mathrm{mM} \mathrm{LiCl}_{1.0 \mathrm{mM} \mathrm{LiNO}_{3}}^{224}$ & 103 & 164 & 4.5 \\
$1.0 \mathrm{mM} \mathrm{LiClO}_{4}$ & 261 & 89 & 175 & 4.1 \\
$0.5 \mathrm{mM} \mathrm{Li}_{2} \mathrm{SO}_{4}$ & 224 & 78 & 151 & 3.9 \\
\hline
\end{tabular}


Table 4. Current and flow rate variations of EOPs using LFP/FP electrodes in different concentrations of $\mathrm{Li}_{2} \mathrm{SO}_{4}$ pumping solutions.

\begin{tabular}{ccccc}
\hline \hline Pumping solution & $\begin{array}{c}\text { Initial current } \\
(\mu \mathrm{A})\end{array}$ & $\begin{array}{c}\text { Final current } \\
(\mu \mathrm{A})\end{array}$ & $\begin{array}{c}\text { Mid-point current } \\
(\mu \mathrm{A})\end{array}$ & $\begin{array}{c}\text { Flow rate } \\
(\mu \mathrm{L} / 30 \mathrm{~s})\end{array}$ \\
\hline $0.2 \mathrm{mM} \mathrm{Li}_{2} \mathrm{SO}_{4}$ & 113 & 51 & 82 & 3.3 \\
$0.5 \mathrm{mM} \mathrm{Li}_{2} \mathrm{SO}_{4}$ & 214 & 112 & 163 & 4.0 \\
$1.0 \mathrm{mM} \mathrm{Li}_{2} \mathrm{SO}_{4}$ & 326 & 136 & 231 & 4.8 \\
$2.0 \mathrm{mM} \mathrm{Li}_{2} \mathrm{SO}_{4}$ & 399 & 178 & 289 & 4.6 \\
$5.0 \mathrm{mM} \mathrm{Li}_{2} \mathrm{SO}_{4}$ & 867 & 290 & 579 & 4.4 \\
$10.0 \mathrm{mM} \mathrm{Li}_{2} \mathrm{SO}_{4}$ & 1414 & 420 & 917 & 3.6 \\
\hline
\end{tabular}

(a)

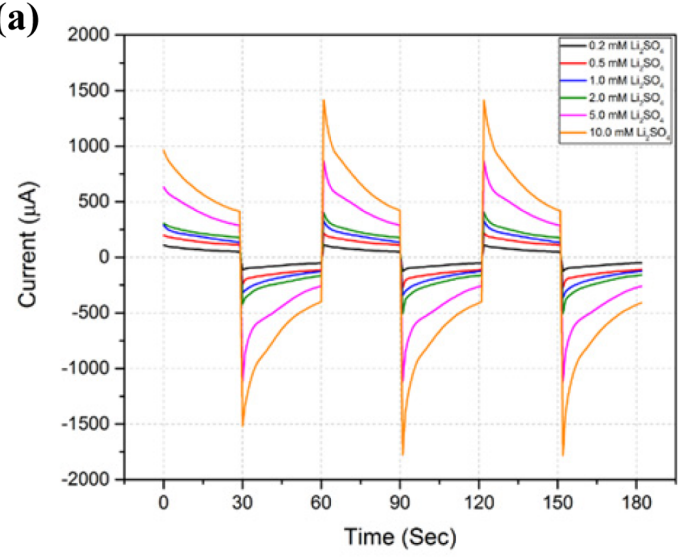

(b)

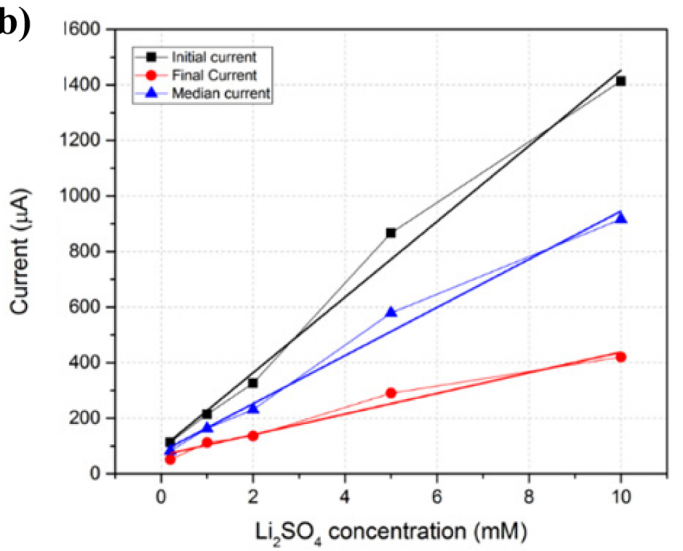

Fig. 6. (a) Current response of EOPs using LFP/FP electrodes in different concentrations of $\mathrm{Li}_{2} \mathrm{SO}_{4}$. (b) Best fit line of current change as a function of $\mathrm{Li}_{2} \mathrm{SO}_{4}$ pumping solution concentration.

observed the change in EOP performance with concentration. The changes in the EOP current and flow rate according to the concentration are summarized in

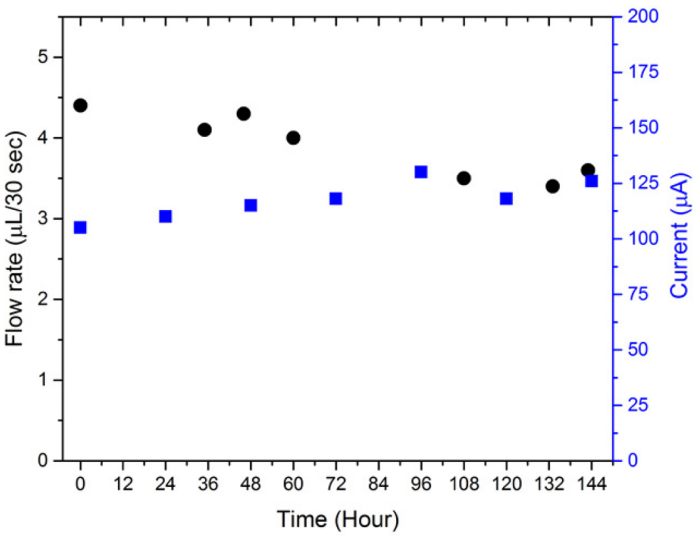

Fig. 7. Continuous running test of EOP using LFP/FP electrodes in $1.0 \mathrm{mM} \mathrm{Li}_{2} \mathrm{SO}_{4}$.

Table 4. In Fig. 6(a), the current increases as the concentration increases. Fig. 6(b) shows best fit lines for the initial, final, and median current changes as a function of $\mathrm{Li}_{2} \mathrm{SO}_{4}$ concentration. The currents increase almost linearly with respect to the concentration of $\mathrm{Li}_{2} \mathrm{SO}_{4}$. However, the increase in the flow rate was not proportional to the change in $\mathrm{Li}_{2} \mathrm{SO}_{4}$ concentration. The flow rate increased for concentrations up to $1.0 \mathrm{mM} \mathrm{Li}_{2} \mathrm{SO}_{4}$, but thereafter the flow rate did not increase even though the concentration of $\mathrm{Li}_{2} \mathrm{SO}_{4}$ increased. This phenomenon can be explained by the fact that when the concentration of $\mathrm{Li}^{+}$transporting water exceeds a certain level, it is no longer used to transport water. Using concentrations of $\mathrm{Li}^{+}$greater than $2 \mathrm{mM}$ increases the ionic concentration of the solution, so that the current increases greatly, but the current is not used to carry any more water. Therefore, the EOP with an LFP/FP electrode 
using $\mathrm{Li}_{2} \mathrm{SO}_{4}$ as a pumping solution showed a maximum flow rate of $4.8 \mu \mathrm{L} / 30 \mathrm{~s}$ at a concentration of $1 \mathrm{mM}$. Also, it was found that the flow rate can be controlled by changing the concentration of $\mathrm{Li}^{+}$in the pumping solution.

Considering the results of LFP/FP electrodes used in EOP tests, of all the pumping solutions tested so far, the $1 \mathrm{mM} \mathrm{Li}_{2} \mathrm{SO}_{4}$ solution was found to be the most effective one. Thus, the newly assembled EOP with an LFP/FP electrode was continuously run in a $1 \mathrm{mM} \mathrm{Li}_{2} \mathrm{SO}_{4}$ solution. As shown in Fig. 7, a stable flow rate of around $4 \mu \mathrm{L} / 30 \mathrm{~s}$ and current of around $120 \mu \mathrm{A}$ were maintained until $144 \mathrm{~h}$ had passed and approximately $34 \mathrm{~mL}$ of fluid was delivered.

\section{Conclusions}

We used LFP, one of the electrode materials of ARLBs, to make electrodes suitable for EOPs. The prepared LFP and FP electrodes were electrochemically tested in $2 \mathrm{M} \mathrm{Li}_{2} \mathrm{SO}_{4}$ solution and the redox reaction of an LFP electrode seems more complex than that of an LFP/FP electrode. Both LFP and LFP/ FP surfaces were used as EOP electrodes and tested in water and $0.5 \mathrm{mM} \mathrm{Li}_{2} \mathrm{SO}_{4}$ solution. In both solutions, the LFP electrode showed too much current; therefore, in terms of EOP efficiency, the LFP/FP electrode was determined to be the appropriate electrode for EOPs.

Experiments using $\mathrm{Li}^{+}, \mathrm{Na}^{+}$, and $\mathrm{K}^{+}$pumping solutions showed that the $\mathrm{Li}^{+}$-containing solution has the lowest current and highest flow rate, but it is not clear whether this is due to the ion size effect or the inherent nature of LFP, as it includes $\mathrm{Li}^{+}$. The difference in current was small when the cation was fixed as $\mathrm{Li}^{+}$ and the anion was changed. Therefore, our EOP transports water through the migration of cations, including $\mathrm{Li}^{+}$, and therefore, the influence of anions is not critical. The performance of EOPs using LFP/ $\mathrm{FP}$ electrodes in different $\mathrm{Li}_{2} \mathrm{SO}_{4}$ concentrations was also tested. With increasing concentration of the $\mathrm{Li}_{2}$ $\mathrm{SO}_{4}$ solution, the current was also observed to increase, but the flow rate showed a maximum value of $4.8 \mu \mathrm{L} / 30 \mathrm{~s}$ in $1.0 \mathrm{mM} \mathrm{Li}_{2} \mathrm{SO}_{4}$ solution and then decreased again. This can be explained by the fact that at concentrations above $2.0 \mathrm{mM}, \mathrm{Li}^{+}$is no longer used for water transport and only increases the ionic strength of the pumping solution, thereby increasing the current. Therefore, it can be said that it is very important that the concentration of the ions in the pumping solution be kept constant in order to maintain the performance of the EOP. A continuous run was performed to determine the stability of the EOP using an LFP/FP electrode in $1.0 \mathrm{mM} \mathrm{Li}_{2} \mathrm{SO}_{4}$, which was determined to be the best pumping solution. The EOP consistently delivered around $35 \mathrm{~mL}$ of fluid over $144 \mathrm{~h}$. We have shown that LFP/FP can be used as the electrode material in EOPs for a long time through reversible voltage swings. The performance of EOPs using LFP/FP electrodes can be varied due to changes in pumping solutions. However, further experiments are needed to clarify the effect of the cation on EOPs using LFP/FP electrodes.

\section{Acknowledgement}

This research was supported by a grant of the Korea Health Technology R\&D Project through the Korea Health Industry Development Institute (KHIDI), funded by the Ministry of Health \& Welfare, Republic of Korea (grant number: HI13C2197).

\section{References}

[1] R. J. Hunter, In Zeta Potential in Colloid Science, Academic Press: 1981.

[2] S. Yao, J. G. Santiago, J. Coll. Interf. Sci., 2003, 268(1), 133-142.

[3] W. Shin, J. M. Lee, R. K. Nagarale, S. J. Shin, A. Heller, J. Am. Chem. Soc., 2011, 133(8), 2374-2377.

[4] W. Shin, E. Zhu, R. K. Nagarale, C. H. Kim, J. M. Lee, S. J. Shin, A. Heller, Anal. Chem., 2011, 83(12), 50235025.

[5] K. Mizushima, P. C. Jones, P. J. Wiseman, J. B. Goodenough, Mater. Res. Bull., 1980, 15(6), 783-789.

[6] R. Yazami, P. Touzain, J. Power Sources, 1983, 9(3), 365-371.

[7] A. K. Padhi, K. S. Nanjundaswamy, J. B. Goodenough, J. Electrochem. Soc., 1997, 144(4), 1188-1194.

[8] Z. Chen, J. R. Dahn, J. Electrochem. Soc., 2002, 149(9), A1184-A1189.

[9] J. Song, B. Sun, H. Liu, Z. Ma, Z. Chen, G. Shao, G. Wang, ACS Appl. Mater. Interf., 2016, 8(24), 1522515231.

[10] H. Manjunatha, T. V. Venkatesha, G. S. Suresh, Electrochim. Acta, 2011, 58, 247-257.

[11] Y. Hou, X. Wang, Y. Zhu, C. Hu, Z. Chang, Y. Wu, R. Holze, J. Mater. Chem. A, 2013, 1(46), 14713-14718.

[12] N. Yesibolati, N. Umirov, A. Koishybay, M. Omarova, I. Kurmanbayeva, Y. Zhang, Y. Zhao, Z. Bakenov, Electrochim. Acta, 2015, 152, 505-511. 
[13] X. Zeng, Q. Liu, M. Chen, L. Leng, T. Shu, L. Du, H. Song, S. Liao, Electrochim. Acta, 2015, 177, 277-282.

[14] N. Alias, A. A. Mohamad, J. Power Sources, 2015, 274, 237-251.
[15] H. D. B. Jenkins, K. P. Thakur, J. Chem. Edu., 1979, 56(9), 576. 